\title{
Ausiàs March ante la tradición trovadoresca ${ }^{1}$
}

\author{
RAFAel Alemany
}

Universitat d'Alacant

Como es sabido, el rasgo que mejor caracteriza al conjunto de la lírica producida por autores catalanes y valencianos de los siglos XIII al XV -0 sea, de la lírica de los Guillem de Berguedà, Guillem de Cabestany y Cerverí de Girona, de los autores del Cançoneret de Ripoll, de la de los hermanos Pere y Jaume March, de los Andreu Febrer, Gilabert de Próixita y Melcior de Gualbes, de los autores del Consistorio poético de Barcelona y, en fin, de Jordi de Sant Jordi- es su dependencia general, con más o menos matices, de la poesía occitano-trovadoresca de los siglos XII y XIII. Ello se constata no sólo en la adopción de los repertorios temáticos del "amor cortés" y de sus sistemas retórico-estilísticos, sino también en el propio código lingüístico que los vehicula: el provenzal clásico hasta el s. XIII y una suerte de hibridación entre éste y el catalán en los ss. XIV y XV. El origen de tan peculiar fenómeno hay que buscarlo en los estrechos vínculos histórico-políticos que unieron el mundo occitano y el catalán desde el siglo XII, ya que, a la muerte de Ramón Berenguer III de Provenza en 1166, le heredó su primo Alfonso - II como rey de Aragón y I como conde de Barcelona-, quien, desde entonces, añadió al título de conde-rey catalano-aragonés el de marqués de Provenza. Esta relación política contribuyó a que la lengua occitana se convirtiera en la lengua de los poetas catalanes y valencianos, determinando que tanto el código lingüístico como el sistema poético al que daba soporte se perpetuara más allá de los límites cronológicos que hubiera cabido esperar, razonablemente, de la particular evolución histórica, social y política de la corona catalano-aragonesa. Ello, a su vez, dio lugar a un anacrónico estancamiento de la lírica autóctona, que, de esta suerte, permaneció aferrada a la vieja tradición trovadoresca y escasamente permeable a los aires renovadores que soplaban desde Italia, país con el que, sin embargo, cada vez más, se estrechaban las relaciones políticas y económicas.

\footnotetext{
' Este trabajo se inscribe en el marco del proyecto de investigación GV/3110/95 de la Conselleria de Cultura, Educació i Ciència de la Generalitat Valenciana.
} 
Un primer hito de la desvinculación progresiva de la dependencia poética catalana con respecto a la lírica occitana fue, sin duda, la batalla de Muret (1213), la cual supuso el fin del esplendor cultural de Occitania y determinó la reorientación estratégica de la Corona de Aragón, que, a partir de entonces, substituyó el signo septentrional de su política exterior por la expansión meridional ibérica y mediterránea, uno de cuyos logros más significativos fue la conquista de la Valencia musulmana por Jaime I en 1236. En lo concerniente a la literatura y, en especial, a la poesía, tal viraje histórico repercute, además, en un alejamiento gradual del sistema poético occitano-trovadoresco por parte de los autores catalanes y valencianos, quienes cada vez más, tienden a introducir en sus composiciones ciertos elementos de renovación temática y formal, entre los cuales sobresale la substitución progresiva del código lingüístico, que, progresivamente, se distancia de la lengua occitana $-\mathrm{y}$, en concreto, del provenzal clásico- hasta llegar a la habilitación definitiva del catalán como lengua poética llevada a cabo por nuestro gran poeta valenciano.

El caballero Ausiàs March ( $c a$. 1400-1459)2 la voz poètica más emblemática de las letras catalanas medievales, vive en Valencia durante los reinados del último monarca de la dinastia catalano-aragonesa, Martín el Humano (1396-1410), y de los dos primeros de la casa de Trastámara en la Corona de Aragón, Fernando de Antequera (1412-1416) y Alfonso el Magnánimo (14161458 ). Se deduce, pues, por razones cronológicas obvias, que la carrera literaria de Ausiàs se desarrolla íntegramente bajo el reinado de Magnánimo, a quien sirvió, primero, militarmente en las primeras campañas mediterráneas que éste llevó a cabo entre 1420 y 1424 (Córcega, Cerdeña, Sicilia, África) y, más tarde, entre 1425 y 1428 como halconero real, cuando ya el poeta había substituido la milicia por la administración de su patrimonio feudal en tierras valencianas.

$\mathrm{Si}$, teniendo en cuenta los condicionamientos histórico-sociales y las opciones estéticas e ideológicas que estos condicionan, aceptamos una división de la historia de la literatura catalana medieval en tres grandes períodos - el que va desde los orígenes hasta el inicio del reinado de Pedro el Ceremonioso, el que se corresponde con los reinados de este monarca y de sus dos hijos Juan y Martín el Humano y, finalmente, el de la etapa de los Trastámara-, se hace evidente que March inaugura el último período, que, por lo demás, es el más brillante y atractivo de los tres tanto por la calidad como por la cantidad y diversidad de textos literarios que se producen a lo largo del mismo.

La hegemonía social, económica y cultural de la antigua Corona de Aragón no siempre residió en un mismo territorio de los muchos que la formaban, sino que, por el contrario, fue cambiando en función de diversas variables históricas. Así, pues, desde la unión dinástica de Cataluña y Aragón en 1137 hasta la culminación de la expansión peninsular y mediterránea llevada a cabo por

\footnotetext{
2 Para una biografía actualizada del poeta, con ricas y novedosas aportaciones documentales - como, por ejemplo, la propuesta de 1400 como año de nacimiento frente a la fecha tradicionalmente aceptada de 1397-, véase Chiner 1997. Para una bibliografía ausiasmarquinna general puede verse Alemany-Martines 1997.
} 
Jaime II en la transición del siglo XIII al XIV, la hegemonía correspondió a Cataluña; a finales del siglo XIV, durante el reinado de Juan I, ésta se desplaza a Aragón y, desde mediados del siglo XV hasta el último tercio del siglo XVI, Valencia se convierte en el reino hegemónico de la Corona. Estos cambios - especialmente el último- hemos de ponerlos en relación con el hundimiento que padeció Cataluña, desde mediados del XIV, a causa de los efectos devastadores de la peste negra, de los conflictos del campesinado - guerra de los payeses de remensa - y urbanos - conflictos de la Biga y la Busca- y, sobre todo, de la guerra civil de los tiempos de Juan II (1462-1472). Valencia, que gozaba de una situación geoestratégica privilegiada, se convirtió en un territorio de acogida de hombres y capitales que huían de la inestabilidad catalana, lo cual ejerció un efecto dinamizador del reino (Reglà, 1975, 43-46).

Es este marco general el que posibilita la espléndida floración literaria de la Valencia cuatrocentista, de la que son exponentes relevantes, además de la poesía de Ausiàs March, la novela caballeresca Tirant lo Blanc (1490), de Joanot Martorell1 ${ }^{3}$ (1405/11-1465), la narración didàctico-burlesca Espill del médico Jaume Roig (fallecido en 1478), la novela teològica Vita Christi (1497) de Isabel de Villena (1430-1490), la poesía, las prosas y las traducciones del teólogo Joan Roís de Corella (1435-1497) y, a un nivel menor, las composicions satíricas y religiosas del beneficiado de la catedral de Valencia Bernat Fenollar (1435/40-1516), del noble Jaume Gassull (fallecido antes de 1515) y de otros autores de su entorno ${ }^{4}$. Todo ello constituye un espléndido tapiz de relaciones personales y literarias (Fuster, 1968, 317-390) tal y como se desprende, por ejemplo, del hecho de que March fuera cuñado de Martorell y se hubiera relacionado con Fenollar o con el padre de Roís de Corella —-si es que no lo estuvo con este mismo-, que muy probablemente sor Isabel de Villena escribiera su Vita Christi con cierta voluntad de réplica implícita al Espill de Jaume Roig (Fuster, 1968, 175-212), que infinidad de páginas del Tirant sean calcos o adaptaciones de textos corellianos (Miralles, 1977-78 y 1991; Garriga, 1991; Hauf, 1993; Guia, 1996), que el mismo Roig participara con Corella en un certamen poético mariano celebrado en Valencia en 1474 o que -por no hacer inacabable la nómina-, a finales del XV, proliferaran una serie de obras fruto de la colaboración entre diversos autores (Cançoner, 1911; Fenollar, 1988).

Pero el trazado de los perfiles básicos del contexto en que se sitúa la figura de Ausiàs March quedaría notoriamente incompleto si no apuntáramos, siquiera de pasada, un par de hechos que, sin duda, guardan relación importante con su poética: uno es de orden histórico, otro de tipo cultural. En primer

\footnotetext{
${ }^{3}$ A falta de pruebas concluyentes a contrario, a mi parecer, prefiero seguir atribuyéndole a Martorell la autoria del Tirant, en contra de otras opiniones y, en especial, de la propuesta muy reciente de Josep Guia (1996).

${ }^{4}$ He aquí, hoy por hoy, las ediciones completas más recomendables de estas obras: March 1912, 1952-59 y 1997; Martorell 1990; Roig 1929-30; Villena 1916; Roís de Corella 1913; Cançoner 1911. Pueden verse también, entre otros: Roís de Corella 1973; Poesia eròtica 1982; Fenollar 1988; Gassull 1989. Para una información bibliográfica más exhaustiva sobre estos autores véase Alemany 1997.
} 
lugar hay que referirse a la entronización de la dinastía castellana de los Trastámara en la confederación catalano-aragonesa a partir del Compromiso de Caspe (1412) y al desplazamiento de la corte real del Magnánimo a Nápoles a partir de 1442. El primero de estos hechos influirá en la iberización progresiva de las letras catalanas - patente en la intensificación de las relaciones con la literatura castellana o en el bilingüismo literario castellano-catalán de bastantes escritores (Ferrando, 1979-82 y 1996; Cocozzella, 1987; Ganges, 1992)—, que, a la vez, implicará el distanciamiento paulatino de los modelos francooccitanos que habían dominado hasta entonces. Por su parte, la importancia del establecimiento definitivo del rey Alfonso en Nápoles radica, más que en la eventual influencia italiana sobre las letras catalanas que de ello se pudo derivar, en la necesidad de crear nuevas plataformas literarias que tal situación generó, a fin de llenar el vacío producido por la ausencia de la corte de los reinos ibéricos de la Corona. No olvidemos que, en torno a la corte y bajo su patronazgo, se había substanciado, secularmente, lo más y mejor de la actividad cultural y literaria (Badia, 1993a): la poesía del trobador áulico Cerverí de Girona, las grandes crónicas, un proyecto gigantesco de inspiración regia como Lo Chrestià de Eiximenis, el Consistorio poético instituido en Barcelona en 1392 por iniciativa real... son muestras elocuentes.

En segundo lugar, hay que aludir al notable papel que ejerció sobre la cultura literaria de la época la concepción del amor difundida a través de la predicación mendicante y de las corrientes del neogalenismo médico. Tal concepción supone un revival del viejo concepto de amor pasión o amor hereos, el cual se concebía como una grave enfermedad psicosomática, de efectos físicos y espirituales sumamente perniciosos para quien la sufre y, por tanto, absolutamente repudiable desde cualquier punto de vista (Cantavella, 1993). Estas teorías constituyen una parte importantísima del trasfondo cultural que se adivina tras una buena parte de la literatura catalana cuatrocentista en general y, muy particularmente, tras los discursos sobre el amor contenidos en las poesías de Ausiàs March, en el Espill del médico Jaume Roig y en la producción en verso y prosa del teólogo Joan Roís de Corella.

Centrándonos ya en Ausiàs March, lo primero que hay que destacar es que su corpus poético, considerado en su conjunto, y más allá de la división tradicional en cantos de amor, de muerte, morales y canto espiritual, establecida por Baltasar de Romaní en el siglo XVI (March, 1539), configura un discurso de fuerte carga moral cuya temática fundamental gira en torno a la experiencia amorosa, sus contradicciones irresolubles y los sufrimientos de todo tipo que de ésta se derivan para el yo poético. El amor humano se nos presenta como un imposible metafísico, en tanto que las exigencias antitéticas del cuerpo y del alma acaban por hacerlo inviable. Por ello el amor en Ausiàs, como en los trovadores, implica la autotortura del enamorado, pero mientras que los poetas occitanos ven en tal padecimiento un medio útil para el perfeccionamento ético, March obtiene unas conclusiones muy diferentes. El poeta valenciano se aplica a destruir la construcción mental de la fin'amor y la substituye por otra de carácter ascético y moralizante (Badia, 1993b, 143-150, Archer, 1994), que 
nos remite a las que, desde tiempo atrás, habían sostenido autores como Marcabrú, Ramon Llull o los propios predicadores mendicantes -recordemos, sin ir más lejos, a San Vicente Ferrer--, todos ellos manifiestamente adversarios del amor cortés y los últimos, en particular, principales divulgadores de las concepciones de la teología cristiana y del neogalenismo médico sobre el mal de amor o amor hereos. Ausiàs se aparta, pues, del universo conceptual propio de las poesías de los trovadores, a quienes, explícitamente, rechaza por haber cantado el amor sensual:

D'aquest voler los trobadors escriuen

e, per aquest, dolor mortal los toca;

la racional part de l'arma no-ls broca;

del sensual aquests apetits viuen.

$$
(87,41-44)^{5}
$$

Pero lo más sorprendente de los planteamientos poéticos de March es que hace coincidir, en un único yo, la experiencia amorosa y la inevitable conciencia de absurdo que esta implica: es decir, el yo poético marquiano, de hecho, parte de posicionamientos análogos a los de un Marcabrú, un Ramon Llull o un San Vicente Ferrer, en lo tocante a la materia amorosa, aunque, pese a ello, paradójicamente, ni puede ni quiere renunciar al amor. Nos hallamos, pues, muy alejados del platonismo cortés que inspiró la poesía trovadoresca y postrovadoresca. El discurso poético de Ausiàs se construye a partir de la dialèctica entre el desideratum de un amor concebido como experiencia espiritual plenaria y la frustrante realidad de un amor inexorablement imbricado con las nociones de sexualidad, de contingencia, de insatisfacción, de sufrimiento y de pecado. El ideal amoroso propugnado que March propugna tan sólo parece poder alcanzarse en el terreno de la realidad virtua1, es decir, como pura construcción mental imaginada:

Ffantasiant, Amor a mi descobre

los grans secrets $\mathrm{c} \cdot$ als pus suptils amaga, e mon jorn clar als hòmens és nit fosqua, e visch de ço que persones no tasten. Tant en Amor l'esperit meu contempla, que par del tot fora del cors s'aparte, car mos desigs no són trobats en home sinó en tal que la carn punt no.l torbe.

Ma carn no sent aquell desig sensible, e l'esperit obres d'amor cobeja; d'aquell cech foch quillls amadors s'escalfen,

${ }^{5}$ Tanto ésta como las restantes citas de los versos de Ausiàs que aparecen en este trabajo proceden de March 1952-59. Entre paréntesis indico, en primer lugar, el número de poema y, en segundo, tras la coma, los versos correspondientes. 
paor no.m trob que yo me'n pogués ardre.

Un altr-esguart lo meu voler pratica

quant en amar- vos, dona, se contenta,

que no han cells qui amadors se mostren

passionats e contra Amor no dignes.

O bien, sorprendentemente, tras producirse la muerte de la amada, en tanto que ésta permite, por fin, liberarse del entorpecedor componente carnal:

Qui ama carn, perduda carn, no ama, mas en membrant lo delit, dol li resta.

En totamor cau amat e amable;

donchs, mort lo cors, aquell qui ell amava

no pot amar, no trobant res que ame.

Amor no viu, desig mort y esperança,

y en lo no res no pot haver espera;

quant és del cors, la Mort a no rres torna.

Si la que am és fora d'aquest segle,

la major part d'aquella és en ésser;

e quan al món en carn ella vivia,

son espirit yo volguí amar simple.

$\mathrm{E}$, donchs, ¿quant més qu·en present res no·m torba?

Ella vivint, la carn m'era rebel.le...

Si la concepción poética del amor en March se aleja, desde un punto de vista conceptual, de la tradición poética occitano-catalana precedente, resulta lógico que Ausiàs rompa también con el código expresivo que había vehiculado aquella para substituirlo por una propuesta linguística, retòrica y estilística muy peculiar y novedosa (Di Girolamo, 1977). En lo que a la lengua se refiere (Sanchis, 1959-62) opta resueltamente por el catalán, un idioma ajeno hasta entonces a los géneros poéticos, pero no, en cambio, a aquellos otros de carácter didáctico y doctrinal -Francesc Eiximenis, San Vicente Ferrer- a través de los cuales se habían transmitido universos nocionales análogos sobre la experiència amorosa; $y$ ello, sin perjuicio, claro está, de la influencia general que, en tal opción, pudo ejercer también la progresiva iberización y desoccitanización de la cultura catalana en época de los Trastámara. Así, pues, a lo largo de los más de 10.000 versos que nos han llegado de March, no alcanzamos a encontrar más de una veintena de formas occitanas, una buena parte de las cuales se explica, pura y simplemente, por exigencias de rima o versificación. Nos hallamos, sin duda, ante un catalán literario exento de provenzalismos - hecho inédito hasta entonces en poesía - y, por lo demás, nada alejado de la lengua de uso corriente. 
En cuanto a la opción retórica y estilística, March forja un lenguage poético anticonvencional y personalísimo (Zimmermann, 1984). Entre los principales elementos caracterizadores de este cabe destacar:

a) El uso de un vocabulario y de unas expresiones propias del registro coloquial y no del aceptado comúnmente como poético:

Bollirà.l mar com la cassola.n forn

Per lo garró que lo rei véu de Caba

Ja no és bo, e més pec és que ruc

$(106,443)$

b) El aprovechamiento poético de una terminologia filosófica y naturalista procedente de enciclopedias escolásticas compiladas en el siglo XIII, tales como el De rerum proprietatibus, de Bartolomeo Ánglico, i los Specula, naturale y doctrinale, de Vicente de Beauvais (Badia, 1997, 42-48). Así, hallamos una alusión a la piedra filosofal $(87,159)$, un repertorio de más de cuarenta especies animales diferentes, provistas del sentido simbólico que les asignaban diversas tradiciones - la clásica, la trovadoresca, la fabulística (la zorra astuta, 111, 39), la de los bestiarios derivados del Phisiologus (el castor, 24, 25-28) o la bíblica (el ciervo herido que busca la fuente, 89,1)-, referencias a los astros $(20,32 ; 14,30 ; 75,2: 27 ; 8,35-36 ; 15,17-18 ; 87$, 331-332), a los cuatro elementos (106, 113-115; 117, 177-180), a las estaciones del año $(2,17 ; 24,37-38 ; 101,97 ; 102,216) \ldots y$, en fin, a un largo etcétera de fenómenos naturales y de elementos propios de los reinos mineral y vegetal.

c) La rentabilización de elementos propios de los discursos de la mística y de la divulgación teológica como materiales constructivos del discurso poético sobre el conocimiento amoroso (Cabré, 1993, Hauf, 1997a).

d) La dureza y la carencia de musicalidad de los versos (Llompart, 1959). El mismo poeta nos advierte que, de sus versos, "l'orella d'om afalach no pot rebre" $(72,36)$, ya que, según nos explica, están escritos "sens algun art, exits d'om fora seny" $(39,6)$.

e) La densidad conceptual.

f) Los peculiares mecanismos de metaforización y comparación (Zimmermann, 1980 y 1991; Archer, 1985 y 1996, 147-200).

g) La presencia de unas imágenes poco plácidas - tempestades y naves que peligran, sepulcros, enfermos, condenados a muerte...-, tal y como se desprende de los siguientes ejemplos: 
Veles e vents han mos desigs complir

ffaent camins duptosos per la mar.

Mestre y ponent contra d'ells veig armar;

xaloc, levant, los deuen subvenir

ab lurs amics lo grech e lo migjorn,

ffent humils prechs al vent tramuntanal

quen son bufar los sia parcial

e que tots cinch complesquen mon retorn.

Si co.l maialt que 1 mege lo fa cert

que no-s pot fer que de la mort escap,

si donchs no beu de verí un anap,

e lo perill no li està cubert,

ne pren a mi, qui vull esperiment

molt perillós e sens ell no pusc viure...

$(59,1-6)$

h) El patetismo retórico -antítesis, paradojas, hipérboles, apòstrofes...(Cocozzella, 1983).

Éstos son algunos de los rasgos más sobresalientes que contribuyen a forjar una poética bastante peculiar, dentro de la cual ocupan un lugar de primer orden los tintes negativos, pesimistas y poco esperanzados, como claramente se deduce de los versos siguientes:

Colguen les gents ab alegria festes, loant a Déu, entremesclant deports; places, carrers e delitables orts sien cerquats ab recont de grans gestes; e vaja yo los sepulcres cerquant, interrogant ànimes infernades, e respondran, car no són companyades d'altre que mi en son contínuu plant.

Cascú requer e vol a son semblant, per ço no.m plau la pràtica dels vius. D’imaginar mon estat són esquius; sí com d'om mort de mi prenen espant.

En suma, cabe afirmar que la contundencia conceptual y la rigidez moral de los planteamientos marquianos se expresa a través de la violencia sintáctica, de imágenes torturadoras y de palabras pretendidamente ásperas: el extremismo estético del autor se corresponde con el extremismo ético que reclama.

Sin embargo, todos estos elementos innovadores són compatibles con una deuda evidente con la poética trovadoresca (Di Girolamo, 1977 y 1997) no sólo 
en lo que afecta a la versificación, los esquemas métricos y estróficos (Ferreres, 1981) y el uso del senyal, o sea, los elementos más externos del corpus poético marquiano, sino también en lo que se refiere a los géneros y a los tópicos literarios. En lo concerniente al estrofismo, del total de 128 composiciones marquianas, 118 están escritas en octavas decasilábicas y, entre estas, abundan las que adoptan el esquema más arquetípico de la canción trovadoresca: cinco octavas con una tornada de cuatro versos. En lo tocante a los senyal ahí están "Plena de seny", "Llir entre cards", "Oh, foll amor" y "Amor, amor" como elementos cohesionadores de los más significativos ciclos poéticos del autor. En cuanto a los géneros, junto a las canciones, conviven también los herederos del sirventés y del maldit provenzales (Archer, 1991), es decir, el reverso de la moneda de la canción amatoria, a través de los cuales el poeta expresa su rechazo a las mujeres, ante la imposibilidad de alcanzar mediante ellas el ideal amoroso anhelado (Archer, 1997):

Maldich lo temps que fuy menys de consell, dones amant més que a mi mateix; ama-les tal qui bé no les coneix, e jo:m confés que fuy lo foll aquell.

$(71,105-108)$

Por otra parte, és también fácil hallar en los poemas de March diversos motivos procedentes de la tópica occitano-trovadoresca, tales como, entre otros muchos, el de la enfermiza e invencible timidez del amante (Pujol, 1991 y 1994), que no le permite revelar su amor a la amada (Hauf, 1997b):

Yo só ben cert que vós no sou ben certa de mon voler, del qual me só callat; ma colpa és, com no'm só clar mostrat, e tal amor no mereix ser cuberta

o el de la muerte por amor:

Llir entre carts, l'ora sent acostada que civilment és ma vida finida; puys que del tot ma sperança.s fugida, m.arma roman en aquest món dampnada.

Habiendo llegado a este punto, y ante un tema como el que propone el título del presente trabajo, parece obligado referirse a los primeros versos del poema 23 , tan reiterada como desacertadamente aducidos para defender la supuesta desafección radical del poeta valenciano a la tradición lírica trovadoresca precedente. Dicen, en efecto, tales versos: 
Lexant a part l'estil dels trobadors

qui, per escalf, trespassen veritat, e sostrahent mon voler affectat perquè no $\cdot \mathrm{m}$ torb, diré 1 que trob en vós.

Esta suerte de exordio poético, con el que se abre el panegírico de la desconocida dama "dona Teresa", no es más que la reformulación del viejo tópico trovadoresco de la veracidad. Lo que Ausiàs viene a decirnos, en suma, es que, a diferencia de las exageraciones habituales con que los poetas suelen cantar a sus damas, él tan sólo se limitará a levantar una suerte de acta notarial de las excepcionales virtudes de la dama, por bien que, como es sabido, al final no logra escapar de las hiperbolizaciones propias del tópico literario que pretende rehuir. Así, pues, cuando March dice aquí que se propone hacer el elogio de la dama dejando de lado el estilo de los trovadores, no pretende otra cosa que hacernos creer que su laudatio será ajustada a la realidad y absolutamente alejada de los elogios convencionales propios de los poetas amatorios más o menos coetáneos suyos. El término "trovador", como bien ha señalado Di Girolamo (1997), se aplica en este caso a los poetas en vulgar en general y no, de forma particularizada, a los trovadores clásicos occitanos, ya que el término "poeta", en el siglo XV, se reservaba para referirse a los creadores en lengua latina y, por tanto, fuera de estos el resto de poetas eran denominados "trovadores". No cabe deducir, pues, de estos versos un rechazo explícito del poeta valenciano a la lírica provenzal precedente ni a sus códigos.

No hay duda alguna de que March conoció a los trovadores clásicos. Como muestra valga el dato que aporta el mismo Di Girolamo (1997), quien llama la atención sobre el hecho de que, a la muerte de Ausiàs, entre los libros que se registran en el inventario notarial correspondiente, se menciona "hun libre en pergamí, cubertes de fusta ab aluda vermella: comença Mestre Miquel de la Tor, es de la Gaya Siciencia”. El tal Miquel de la Tor, que vivió a caballo de los siglos XIII y XIV, es, entre otras cosas, el compilador de un rico y prestigioso cancionero antológico en el que están representados los más importantes trovadores clásicos de los siglos XII y XIII. Por tanto, el códice del Mestre Miquel de la Tor que Ausiàs conservaba en su domicilio de Valencia en el momento de su muerte debía ser una copia de este importante cancionero. Tal circunstancia permite sostener que, aun en el supuesto de que el poeta valenciano a lo largo de toda su vida sólo hubiera podido acceder a los trovadores provenzales a través de este códice, le hubiera bastado para leer allí un buen número de composiciones trovadorescas $\mathrm{y}$, en consecuencia, lograr un grado considerable de familiarización con los cánones de la poética occitana.

Pero la tradición occitano-trovadoresca no es más que el punto de partida de la obra de March, ya que el poeta valenciano amplía y supera el universo estético y conceptual de aquella. Esto lo consigue, fundamentalmente, a través de la introducción en sus versos de un psicologismo amoroso de inspiración tomista (Cocozzella, 1990 y 1991) — patente, sobre todo, en los extensos poemas en que 
se describe con detalle la naturaleza de la pasión amorosa - y a través de la reflexión moral y religiosa, a menudo de evidente raíz homilética (Rico, 1982). De esta suerte, el poemario de March acaba destruyendo, por superación, la poética occitano-trovadoresca, y ello tanto por la negación de los referentes conceptuales últimos de aquella, como por el rechazo del provenzal como vehículo poético.

Ausiàs March revoluciona, sin duda, la poesía de su tiempo, a partir de una reformulación muy personal del viejo código trovadoresco. Sin embargo, esta revolución no se caracteriza precisamente por el acercamiento a las innovaciones poéticas de signo petrarquista que triunfaban en Italia (Lapesa, 1948). Nada más alejado de March que la musicalidad de los versos de Petrarca, aunque a ambos poetas les acerque la actitud de anhelo y rechazo simultáneos del amor humano. Las poéticas de estos dos autores, aun proviniendo de la fuente común de la tradición trovadoresca, evolucionan hacia dos resultados totalmente originales y diversos. Todo el culto al ornato retórico que Ausiàs nos niega una y otra ve $z^{6}$, Petrarca nos lo ofrece porque, precisamente, para él la retórica forma parte indisoluble de la poetización de la experiencia amorosa, es decir, se siente seducido por una pasión que tiene mucho que ver con la estética y la retórica. El rechazo marquiano del esteticismo formal lo sitúa al margen de las propuestas de renovación poética y cultural que, a la sazón, ya se habían iniciado en otras partes de Europa, lo cual no implica, necesariamente, una ignorancia total de los ingredientes literarios de tales propuestas renovadoras, tal y como se desprende del hecho de que March evidencie en más de un lugar de su poemario un cierto grado de conocimiento de la cultura clásica y hasta del propio Petrarca (Badia, 1993b, 195-207). Pero, en cualquier caso, lo que conviene tener en cuenta, para concluir, es que el gran poeta valenciano cuatrocentista innova desde el respeto más absoluto a los parámetros morales y didascálicos más genuinos del mundo medieval.

\section{REFERENCIAS BIBLIOGRÁFICAS}

ALEMANY, Rafael (1997), Guia bibliogràfica de la literatura catalana medieval, $2^{a}$ edición revisada, corregida y aumentada, Alicante, Secretariat de Publicacions de la Universitat d'Alacant ( $1^{4}$ ed. 1995).

- I ViCENT Martines (1997), "Bibliografia sobre Ausiàs March", en Ausiàs March: textos $i$ contextos, Alicante-Barcelona, Institut Interuniversitari de Filologia Valenciana-Departament de Filologia Catalana de la Universitat d'Alacant-Publicacions de l'Abadia de Montserrat, pp. 365-408.

ARCHER, Robert (1985), The Pervasive Image. The Role of Analogy in the Poetry of Ausiàs March, Amsterdam-Philadelphia, John Benjamins.

\footnotetext{
" No olvidemos que, según el mismo poeta declara, de sus versos "l'orella d'om afalach no pot rebre" $(72,36)$ y, además, están escritos "sens algun art, exits d'om fora seny" $(29,6)$.
} 
- (1991), "Tradition, Genre, Ethics and Politics in Ausiàs March's maldit", Bulletin of Hispanic Studies, LXVIII, pp. 371-382.

- (1994), "Ausiàs March as a Theorist of Love", en The Discerning Eye. Studies presented to Robert Pring-Mill on his Seventieth Birthday, ed. de Nigel Griffin, Clive Griffin Eric Southwort y Colin Thompson, Oxford, The Dolphin Book Co., pp. 316.

- (1996), Aproximació a Ausiàs March, Barcelona, Empúries.

- (1997), "Ausiàs March i les dones", en Ausiàs March: textos $i$ contextos, edición al cuidado de Rafael Alemany, Alicante-Barcelona, Institut Interuniversitari de Filologia Valenciana-Publicacions de l'Abadia de Montserrat, pp. 13-30.

BADIA, Lola (1993a), "Literatura catalana i patronatge reial al segle XV: episodis d'un distanciament", Pedralbes. Revista d' Història Moderna, 13, 2 (=Actes del Tercer Congrés d' Història Moderna de Catalunya: les Institucions Catalanes [segles XVXVIIJ), pp. 525-534.

- (1993b), Tradició i modernitat als segles XIV i XV. Estudis de cultura literària i lectures d'Ausiàs March, Valencia-Barcelona, Institut de Filologia ValencianaPublicacions de l'Abadia de Montserrat.

- (1997), "Ausiàs March i l'enciclopèdia natural: dades científiques per a un discurs moral", en Ausiàs March: textos i contextos, edición al cuidado de Rafael Alemany, Alicante-Barcelona, Institut Interuniversitari de Filologia ValencianaDepartament de Fiolologia Catalana de la Universitat d'Alacant-Publicacions de l'Abadia de Montserrat, pp. 31-57.

CABRÉ, Lluís (1993), “Apunts sobre la subtilesa en la poesia d'Ausiàs March", en Actes del Novè Col-loqi Internacional de Llengua i Literatura Catalanes (Alacant-Elx, 9-14 de setembre de 1991), I, ed. de Rafael Alemany, Antoni Ferrando i Lluís B. Meseguer, Publicacions de l'Abadia de Montserrat, Universitats d'Alacant, de València i Jaume I de Castelló, pp. 273-287.

Cançoner 1911 = Cançoner satíric valencià, ed. de Ramon Miquel i Planas, Barcelona.

CANTAVELla, Rosanna (1993), "Terapèutiques de l'amor hereos a la literatura catalana medieval", en Actes del Novè Colloqui Internacional de Llengua i Literatura Catalanes (Alacant-Elx, 9-14 de setembre de 1991), II, ed. de Rafael Alemany, Antoni Ferrando i Lluís B. Meseguer, Barcelona-Alicante-Valencia-Castellón, Publicacions de l'Abadia de Montserrat-Universitats d'Alacant, València i Jaume I, pp. 191-207.

Cocozzella, Peter (1983), "Contrast, Conflict, Crisis: A Paradigm for an Aesthetics of Ausiàs March's poems", en Actes del Tercer Col-loqui d'Estudis Catalans a Nord-Amèrica (Toronto, 1982), Barcelona, Publicacions de l'Abadia de Montserrat, pp. 169-186.

- (1987), "Pere Torroella i Francesc Moner: aspectes del bilingüisme literari (catalano-castellà) a la segona meitat del segle XV", Llengua \& Literatura, 2, pp. 155 173.n

- (1990), "Ausiàs March's Encyclopedic Form: Toward a Poetic of Syncretism", Roman Languages Annual 1989, ed. de B. Lawton y A. J. Tamburri, West Lafayette (Indiana), The Padrue Research Fundation, pp. 399-408. 
- (1991) "Ausiàs March's Sainted Eros: A Model of Christian Syncretism", Catalan Review, V, 1, July, pp. 79-94.

Di Girolamo, Costanzo (1977), "Ausiàs March and the trobadour poetic code", en Catalan Studies in Memory of Josephine de Boer, ed. de Joseph Gulsoy y Josep M. Solàs Solé, Barcelona, Borràs, pp. 223-237.

Di Girolamo, Costanzo (1997), "Ausiàs March i la tradició occitana", Avui. Suplement "Ausiàs March (1397-1997)": sis-cents anys del naixement, 23-5-1997, pp. XXXVIII-XLII.

Fenollar, Bernat, et al. (1988), Lo procés de les olives. Lo somni de Joan Joan, ed. de Vicent Pitarch i Lluis Gimeno, estudi introductori de Salvador Jàfer, València, Tres i Quatre.

FERRANDO, Antoni (1979-82), "Un precedent del bilingüisme literari valencià: la tertúlia d'Isabel Suaris a la València quatrecentista", Boletín de la Real Academia de Buenas Letras (Barcelona), XXXVIII, pp. 105-131.

- (1996), "El concepte d'escola valenciana aplicat als poetes valencians de l'època de Fenollar: consideracions sobre el seu bilingüisme", en Essays in Honor of Josep M. Solà-Solé: Linguistic and Literary Relations of Catalan and Castilian, ed. de Suzanne S. Hintz, New York, Peter Lang, pp. 199-217.

FERreres, Rafael (1981), "La mètrica d'Ausiàs March", Revista Valenciana de Filología, VII, 4, pp. 313-349.

FUSTER, Joan (1968), Obres completes, I, Barcelona, Edicions 62.

GANGES GARRIGA, Montserrat (1992), "Poetes bilingües (català-castellà) del segle XV", Boletín de la Asociación Hispánica de Literatura Medieval, 6, 1, pp. 57-232.

GarRIGA, Carles (1991), "Caldesa i Carmesina: Roís de Corella plagiat en el Tirant lo Blanc", en Estudis de Llengua i Literatura Catalanes, XXIII (=Miscel-lània Jordi Carbonell, 2), Barcelona, Publicacions de l'Abadia de Montserrat, pp. 17-27.

GaSsull, Jaume (1989), Obra religiosa, ed. de Rosanna Cantavella i Salvador Jàfer, València, Edicions Alfons el Magnànim.

GuiA I MARÍN, Josep (1996), De Martorell a Corella. Descobrint l' autor del "Tirant lo Blanc", Catarroja-Barcelona, Afers.

Hauf, Albert G. (1993), "Tirant lo Blanc: algunes qüestions que planteja la connexió corelliana", en Actes del Novè Col-loqui Internacional de Llengua i Literatura Catalanes, II, ed. de Rafael Alemany, Antoni Ferrando y Lluís B. Meseguer, Barcelona-Alicante-Valencia-Castellón, Universitats d'Alacant, València i Jaume I, pp. 69-116.

- (1997a), "L'apocalipsi marquià. Ausiàs March, místic i profeta de l'amor humà", en Rafael Alemany (ed.), Ausiàs March: textos $i$ contextos, Alicante-Barcelona, Institut Interuniversitari de Filologia Valenciana-Departament de Filologia Catalana de la Universitat d'Alacant-Publicacions de l'Abadia de Montserrat, pp. 191220.

- (1997b), “Ausiàs March: el clamor del silenci”, L'Illa, revista de lletres, 18, pp. 610. 
LAPESA, Rafael (1948), "Ausiàs March, Petrarca y la poesía castellana del siglo XV", en La trayectoria poética de Garcilaso, Madrid, Revista de Occidente, 1968².

Llompart, Josep Maria (1959), “Ausiàs March i el prosaisme”, Ponent, XI, pp. 12-25.

[MARCH, Ausiàs] (1539), Las obras del famosíssimo philósofo y poeta Mosén Osias Marco [...], traduzidas por don Baltasar de Romaní [...]. Dirigidas al excelentíssimo señor duque de Calabria, València, Juan Navarro (ed. facsímil en 2 vols., al cuidado de Vicent J. Escartí, Valencia, Bancaixa, 1997).

- (1912), Les obres d'Auzias March, 2 vols., ed. de Amédée Pagès, Barcelona, Institut d'Estudis Catalans, 1912 (ed. facsímil: València, Consell Valencià de Cultura de la Generalitat Valenciana, 1991, 1995²).

- (1952-59), Poesies, 5 vols., ed. de Pere Bohigas, Barcelona, Barcino ("Els Nostres Clàssics", 71-73, 77 y 86).

- (1997), Obra completa, 2 vols., ed. de Robert Archer, Barcelona, Barcanova.

Martorell, Joanot, (i Martí Joan de Galba?) (1990), Tirant lo Blanch, e vols., ed. d'Albert G. Hauf y Vicent J. Escartí, València, Conselleria de Cultura, Educació i Ciència de la Generalitat Valenciana (2a ed., corregida, 1992).

MiRAlles, Carles (1977-78), "Raons de Mirra en boca d'Esperança. (Sobre un altre plagi de Roís de Corella en el Tirant lo Blanc)", Boletín de la Real Academia de Buenas Letras de Barcelona, XXXVII, pp. 141-147 (reed. en Carles Miralles, Eulàlia, estudis i notes de literatura catalana, Barcelona, Edicions del Mall, 1986, pp. 51-62).

- (1991), "Raons de Mirra en boca de Carmesina. (Encara un altre plagi de Roís de Corella en el Tirant lo Blanc)", en Estudis de llengua i literatura catalanes, XXIII (=Miscel-lània Jordi Carbonell, 2), Barcelona, Publicacions de l'Abadia de Montserrat, pp. 5-16.

Poesia eròtica 1982 = Poesia eròtica i burlesca dels segles XIV i XV, I, ed. de Vicent Pitarch i Lluis Gimeno, València, Tres i Quatre.

PujoL, Josep (1991), "L'experiment molt perillós i la vida moral de l'amant tímid. A propòsit del poema LIX d'Ausiàs March", Serra d'Or, 337, mayo, pp. 56-59.

- (1994), "Ausiàs March i la timidesa de l'enamorat: una lectura del poema LIX", en Textos literaris catalans. Lectures i interpretacions, I, ed. de Narcís Garolera, Barcelona, Columna, pp. 101-116.

REGLÀ, Joan (1975³), Aproximació a la història del País Valencià, València, Editorial Eliseu Climent.

Rico, Francisco (1982), "Lo viscahí qui-s troba·n Alemanya", en Primera cuarentena y tratado general de la literatura, Barcelona, El Festín de Esopo, pp. 85-87. Reed.: "Sylvae (XXI-XXV)", en Estudis de llengua i literatura catalanes oferts a Ramon Aramon i Serra en el seu setantè aniversari, 4, Barcelona, Curial, pp. 233-237.

RoIG, Jaume (1929-30), Spill o Llibre de consells, 3 vols., ed. de Ramon Miquel i Planas, Barcelona.

- (1981), Espill o Llibre de les dones, Barcelona, Edicions 62-La Caixa.

[Roís De CoRella, Joan] (1913), Obres de Joan Roís de Corella, edició de Ramon Miquel i Planas, Barcelona. 
- (1973), Obra profana, a cura de Jordi Carbonell, València, Albatros ( $2^{\text {a }}$ ed. Valencia, Tres i Quatre, 1983).

Sanchis Guarner, Manuel (1959-62), "La lengua de Ausiàs March", Revista Valenciana de Filología, VI, pp. 85-99.

Villena, Isabel de (1916), Vita Christi, 3 vols., ed. de Ramon Miquel i Planas, Barcelona, 1916.

- (1995), Vita Christi: antologia, ed. d'Albert G. Hauf, Barcelona, Edicions 62-La Caixa.

ZIMMERMANN, Marie-Claire (1980), "Metàfora i destrucció del món en Ausiàs March", en Actes del Cinquè Col-loqui Internacional de Llengua i Literatura Catalanes (Andorra, 1-6 d'octubre de 1979), a cura de Jordi Bruguera i de Josep Massot, Barcelona, Publicacions de l'Abadia de Montserrat, pp. 123-150 (reed. en Zimmermann 1998, pp. 287-313).

- (1984), La solitude d'Ausiàs March. Recherches sur la naissance et le devenir d'un style dans la poésie ibérique, 2 vols., París.

- (1991), "La comparaison et la substantification dans l'oeuvre d'Ausiàs March: recherches sur les nouvelles fonctions poétiques de l'image", en Studia in honorem prof. $M$. de Riquer, IV, Barcelona, Quaderns Crema, pp. 119-150 (traducción catalana en Zimmermann 1998, pp. 115-140).

- (1998), Ausiàs March o l'emergència del jo, pròleg d'Albert Hauf, Valencia-Barcelona, Institut Interuniversitari de Filologia Valenciana-Publicacions de l'Abadaia de Montserrat. 